\title{
Philosophiques
}

\section{Livres reçus}

Volume 23, numéro 1, printemps 1996

Critères esthétiques et métamorphoses du beau

URI : https://id.erudit.org/iderudit/027391ar

DOI : https://doi.org/10.7202/027391ar

Aller au sommaire du numéro

Éditeur(s)

Société de philosophie du Québec

ISSN

0316-2923 (imprimé)

1492-1391 (numérique)

Découvrir la revue

Citer ce document

(1996). Livres reçus. Philosophiques, 23(1), 211-213.

https://doi.org/10.7202/027391ar

Ce document est protégé par la loi sur le droit d'auteur. L'utilisation des services d'Érudit (y compris la reproduction) est assujettie à sa politique d'utilisation que vous pouvez consulter en ligne.

https://apropos.erudit.org/fr/usagers/politique-dutilisation/
Cet article est diffusé et préservé par Érudit.

Érudit est un consortium interuniversitaire sans but lucratif composé de l’Université de Montréal, l'Université Laval et l'Université du Québec à Montréal. Il a pour mission la promotion et la valorisation de la recherche. https://www.erudit.org/fr/ 


\section{LIVRES REÇUS}

Baertschi, Bernard, La valeur de la vie humaine et l'intégrité de la personne, Paris, PUF (coll. "Philosophie morale"), 1995, vi$314 \mathrm{p}$.

Bidima, Jean-Godefroy, La philosophie négro-africaine, Paris, PUF (coll. "Que sais-je? " $\mathrm{n}^{\circ}$ 2985), 1995, $128 \mathrm{p}$.

Bonfand, Alain, L'expérience esthétique à l'épreuve de la phénoménologie. La tristesse du roi, Paris, PUF, 1995, 125 p.

Boulad-Ayoub, Josiane, Mimes et parades. L'activité symbolique dans la vie sociale, Paris, L'Harmattan, (coll. "La philosophie en commun "), 1995, 384 p.

Bourgeois, Bernard, La philosophie allemande classique, Paris, PUF (coll. "Que sais-je ?" $n^{\circ}$ 1466), Paris, PUF, 1995, 128 p.

Boutot, Alain, La pensée allemande moderne, Paris, PUF (coll. "Que sais-je ? " $n^{\circ} 2991$ ), 1995, 128 p.

Bouvier, Alban, L'argumentation philosophique. Étude de sociologie cognitive, Paris, PUF (coll. "Sociologies"), 1995, 248 p.

Brunschwig, Jacques, Études sur les philosophies hellénistiques (Épicurisme, stoïcisme, scepticisme), Paris, PUF (coll. "Épiméthée "), 1995, $364 \mathrm{p}$.

Carnier, Andrè et al., Apologie de Socrate: introduction à la philosophie, Montréal, CEC (coll. "Philosophies vivantes "), 1995. $216 \mathrm{p}$.

Carignan, Maurice, Essai sur l'Intermède de Kierkegaard, Ottawa, Presses de l'Université d'Ottawa (coll. "Philosophica "), 1995, x219 p.

Crowe, Frederick E., Bernard J. F. Lonergan. Progresso et Tappe del suo pensiero, Roma, Città Nuova Editrice, 1995, 192 p.

Deledalle, Gérard, La philosophie peut-elle être américaine? Nationalité et universalité, Paris, Éd. J. Grancher, 1995, 304 p.

Dorion, Louis-André, Aristote : Les réfutations sophistiques, Introduction, traduction et commentaire, Paris-Québec, Vrin-Presses de l'Université Laval (coll. "Histoire des doctrines de l'Antiquité classique " 18), 1995, x-476 p.

Dworkin, Ronald, Prendre les droits au sérieux, Paris, PUF (coll. "Léviathan "), 1995, 515 p. 
Gauthier, Yvon, La philosophie des sciences. Une introduction critique, Montréal, Presses de l'Université de Montréal, 1995, xi$130 \mathrm{p}$.

Guillon, Emmanuel, Les philosophies bouddhistes, Paris, PUF (coll. "Que sais-je?" $\mathrm{n}^{\circ} 3003$ ), $128 \mathrm{p}$.

Hartz, Louis, La nécessité du choix. La pensée politique au XIXe siècle, (traduit de l'anglais par P.-E. Dauzat), Paris, PUF (coll. "Perspectives critiques "), 1995, 254 p.

Hayek, Friedrich A., Droit, législation et liberté, Paris, PUF (coll. "Quadrige "), 1995, 3 volumes.

Houde, Olivier, Rationalité, développement et inhibition. Un nouveau cadre d'analyse, Paris, PUF (coll. "Psychologie et sciences de la pensée "), 1995, $146 \mathrm{p}$.

Laflamme, Simon, Communication et émotion. Essai de microsociologie relationnelle, Paris, L'Harmattan, 1995, 191 p.

Lafrance, Yvon \& Paquet, Léonce, Les Présocratiques. Bibliographie analytique (1450-1879), Montréal, Bellarmin (coll. "Noêsis"), 1995, 429 p.

Larochelle, Gilbert, Philosophie de l'idéologie. Théorie de l'intersubjectivité, Paris, PUF (coll. "L'interrogation philosophique "), 1995, vii-274 p.

Locke, John, Lettre sur la tolérance, [texte latin et traduction française), (trad. du latin par R. Polin), Paris, PUF (coll. "Guadrige "), 1995, xcix-107 p.

Macherey, Pierre, Introduction à l'Éthique de Spinoza. La cinquième partie: les voies de la libération, Paris, PUF (coll. "Les grands livres de la philosophie "), 1994, vi-230 p.

Misrahi, Robert, Existence et démocratie, Paris, PUF (coll. "Questions *), 1995, 244 p.

Moritz, Karl Philipp, Le concept d'achevé en soi et autres écrits (17851793), [textes présentés et traduits par P. Beck], Paris, PUF (coll. "Philosophie aujourd"hui "), 1995, 235 p.

Müller, Friedrich, Discours de la méthode juridique, (trad. de l'allemand par O. Jouanjan), Paris, PUF (coll. "Léviathan "), 1996, $438 \mathrm{p}$.

Nouss, Alexis, La modernité, Paris, PUF (coll. "Que sais-je?" $\mathrm{n}^{\circ}$ 2923), 1995, $128 \mathrm{p}$.

Patar, Benoit, Nicolai Oresme: Expositio et quastiones in Aristotelis De Anima, [texte et étude critiquel, Louvain-la-Neuve / Paris, Éd. de l'Institut supérieur de philosophie / Éd. Peeters, 1995, clxxxi619 p.

Rawls, John, Libéralisme politique, Paris, PUF (coll. "Philosophie morale ), $1995,450 \mathrm{p}$. 
Rosen, Stanley, Plato's Statesman : the web of politics, New Haven, Yale University Press, 1995, x-197 p.

Schultz, Johann, Exposition of Kant's Critique of Pure Reason, (trad. de l'allemand par J. C. Morrison), Ottawa, Presses de l'Université d'Ottawa (coll. "Philosophica "), 1995, xxxi-216 p.

Spitz, Jean-Fabien, La liberté politique, Paris, PUF (coll. "Léviathan "), 1995, $509 \mathrm{p}$.

Vargas, Yves, Introduction à l'Émile de Rousseau, Paris, PUF (coll. "Les grands livres de la philosophie "), 1995, vii-344 p.

Les personnes désireuses de faire un compte rendu de l'un ou lautre des ouvrages qui apparaissent dans cette liste sont priêes de s'adresser à :

Louis-André Dorion

Université de Montréal

Département de philosophie

C.P. 6128, Succ. Centre-Ville

Montréal, Qc. H3C 3J7

têl.: (514) 343-6020

fax: (514) 343-7899

E-mail: dorionl@ere.umontreal.ca 